\title{
Effect of Late Pregnancy Self-Perineal Massage on the Perineal State of the Primi- parturients
}

Nadia Youssef Abd-Ella( ${ }^{(1)}$, Hanan Abderahman Mostafa Kandeel (2), Ahlam

Mohammed Ibrahim Gouda ${ }^{(3)}$

${ }^{(1)}$ Lecturer of Woman's Health \& Midwifery, Nursing Department, Faculty of Nursing, Mansoura University, Egypt

${ }^{(2)}$ Assistant professor of Obstetric and Gynecologic Nursing, Faculty of Nursing, Alexandria University, Egypt

(3) Assistant professor of Woman's Health \& Midwifery, Nursing Department, Faculty of Nursing, Mansoura University, Egypt

\begin{abstract}
Perineal massage help to stretch the vaginal opening and surrounding perineal muscles through applying of external manual pressure, It increases the flexibility of the perineal muscles, thereby reducing muscle resistance, causing the perineum to stretch during labor without rupture and no need for an episiotomy. Aim: This study aimed to assess the effect of late pregnancy self-perineal massage on the perineal state of the primi-parturients. Methods: Quasi experimental design was used to conduct this study at a private hospital of obstetrics and gynecology specialty at El- Mahalla El -Kobra city, Gharbia Governorate, Egypt. A nonprobability purposive sample of 68 pregnant women were invited to participate in the study and were divided into two groups ( $\mathrm{n}=34$ per each group); the intervention group (underwent late pregnancy self-perineal massage) and control group (underwent conventional hospital protocol of care). Two tools were used to collect the data; the first tool was a structured interview schedule to assess participants' basic characteristics. The second tool was assessment sheet to assess the duration of labor, perineal state and neonatal outcomes after delivery. Results: Post intervention, there was statistical significant difference between the studied groups regarding perineal trauma in which $82.4 \%$ of the subjects in the perineal massage group had intact perineum compared to $64.7 \%$ of the control group. The mean duration of second stage of labor was shorter in the perineal massage group compared to control group $(54.411 \pm 3.105 \& 57.176 \pm 2.989$, respectively). Conclusion: The current study findings highlighted those primi-parturient women who perform late pregnancy selfperineal massage exhibits shorter duration of labor and experiences lower perineal trauma as well as reports lower postpartal perineal pain. This study recommended that late pregnancy self-perineal massage technique should be considered as a part of the routine perinatal care to reduce the incidence of perineal trauma.
\end{abstract}

Keywords: late pregnancy, perineal massage, perineal state \&Primi-parturients. 


\section{Introduction}

Trauma of the perineum during labor is a common health problem most likely for primiparous women ${ }^{(\mathbf{1})}$. It can be defined as any injury of the genitalia during labor which occurs either naturally as a laceration or intentionally as episiotomy (2). The incidence of perineal trauma is relatively high as it reaches to eighty five percent and approximately sixty to seventy percent needs suturing $(3,4)$.

Numerous factors can lead to perineal injury including both the mother and fetus as null parity, maternal obesity, fetal macrosomia, mal-presentation and malposition ${ }^{(5)}$.Other risk factors include operative vaginal deliveries, precipitous labor, and fundal pressure ${ }^{(6,7)}$.Indeed, women who have suffered severe perineal trauma throughout their labor may have short or long term effects because the damaged perineum may result in postpartum hemorrhage, weakness of the pelvic floor muscle, persistent post-partum perineal pain that affect sexual function due to dyspareunia, frustration which affect the mother's ability to care of her baby and negatively affect maternal child bonding $(3,8,9)$.

Generally, maternity nurses' primary goal of care focuses on the preservation of the perineum to be intact during delivery in order to reduce unnecessary perineal trauma, which may lead to negative birth experience ${ }^{(10)}$. They are responsible for looking for new strategies that can reduce the perineal tears and improves postpartum perineal outcomes as pelvic floor muscle training and perineal massage during pregnancy $(2,11)$.

Perineal massage is known as a therapeutic technique that promotes muscle relaxation, vasodilation of blood vessels, and increases the perineal stretch ability upon increased blood circulation (12). When perineal massage is provided by the woman herself it is called Self-Perineal Massage (SPM) which aims to enhance perineal muscles flexibility, thus reducing muscle resistance, allowing the perineum to stretch during labor without tearing and without the need for episiotomy.SPM also works on the reduction of perineal pain, reducing burning sensation during labor and reducing labor duration especially the $2^{\text {nd }}$ stage ${ }^{(2,13)}$. However the evidence about the effectiveness of SPMis not strong enough to recommend it universally. Meanwhile, few studies have indicated that SPM in the late weeks of pregnancy had a significant impact on keeping perineal integrity, reducing the incidence of perineal trauma $(\mathbf{1 3 , 1 4 )}$. 


\subsection{Significance of the study}

In spite of effort exerted on practical issues of perineal trauma, it remains present and is still growing because most of primiparous women suffer from child birth morbidity from episiotomy and or perineal trauma. Perineal trauma occurs in $85 \%$ of all women who experience vaginal delivery ${ }^{(9)}$. Only one out of four women came through labor and delivery with an intact perineum (1). Meanwhile, the incidence of perineal trauma among Egyptian women is relatively high,Mosad et al. $(\mathbf{2 0 1 7})^{(15)}$ reported that, $70,8 \%$ of their subjects had perineal trauma, in which $36.3 \%$ of them had episiotomy and $34.5 \%$ of them had perineal tear with $46.2 \%$ had $2^{\text {nd }}$ degree of perineal tears.

SPM in later weeks of pregnancy has been introduced as a technique for reducing perineal trauma ${ }^{(16)}$. Despite the advantages of SPM and recommendations that pregnant women should perform it, doubts have been raised about its efficacy and its use remains controversial ${ }^{(17)}$. In Egypt there is limited research addressing the effect of SPM on the incidence of perineal trauma. This shows the need for conducting this study to assess the effect of late pregnancy self-perineal massage on the perineal state of the primi-parturients.

\subsection{Operational definitions:}

- Late pregnancy: refers to the later weeks of pregnancy begins at 34 weeks until birth.

- Perineal trauma: refers to any damage of the area between the vagina and the anus during delivery of a baby including spontaneous perineal laceration and episiotomy.

- Perineal state: is the assessment of perineal outcomes after delivery including the incidence of perineal trauma and postpartal perineal painlevel.

- Perineal Massage: involves insertion of one or two lubricated fingers approximately three to five $\mathrm{cm}$ into the vagina with a constant static pressure exerted along the lower lateral areas of the perineum.

- Self-Perineal Massage (SPM): when perineal massage is provided by the woman herself, it is called selfperineal massage.

\subsection{Aim of the study:}

This study aimed to assess the effect of late pregnancy self-perineal massage on the perineal state of the primi-parturients.

\subsection{Hypotheses of the study:}

To achieve the study aim, three hypotheses were tested:

- Primi-parturient women who perform late pregnancy self-perineal massage exhibit shorter duration of labor than 
those who do not.

- Primi-parturient women who perform late pregnancy self-perineal massage experience lower perineal trauma than those who do not.

- Primi-parturient women who perform late pregnancy self-perineal massage rate lower postpartal perineal pain than those who do not.

\section{Subjects and Method:}

\subsection{Research design:}

A quasi-experimental research design was utilized to achieve the aim of the study; where the effect of the independent variable (i.e., late pregnancy self-perineal massage) on the dependent variables (perineal state i.e., the incidence of perineal trauma, postpartal perineal pain and the duration of labor) were assessed in this study.

\subsection{Study Setting:}

The study sample was recruited from the Obstetrics and Gynecology outpatient clinic at El- Mahalla El -Kobra city, Gharbia Governorate, Egypt and followed up until delivery. Two sites in the hospital were involved; the Obstetrics and Gynecology outpatient clinic where the study sample was recruited from and provided with the instructions about perineal massage (consisted of reception, patient's waiting-area, laboratory lab, and three examination rooms for 4D ultrasound and routine examination) and the labor and delivery unit where the studied subjects were delivered and assessed for study outcomes (consisted of three operating theaters for normal and caesarian section deliveries, gynecological operations and recovery rooms). The rational for selecting this setting is the higher utilization of their services by pregnant and parturient women.

\subsection{Sampling}

A non-probability purposive sample of 68 pregnant women was invited to participate in the study during the period from the first of November 2020 till the end of April 2021. Women who joined this study have to fulfill the following inclusion criteria: primiparous women, gestational age of 35 weeks, expected to deliver normally, had single viable fetus with normal position and presentation, free from genital infection ( e.g. genital herbs, genital warts, ulcers and yeast infection )as well as had good pelvic-floor muscle contraction (i.e. brink score of 10-12).

\subsection{Sample size:}

Sample size was calculated using $\mathrm{G}$ power program version 3.1.9.4 by the aid of using the following data: the mean difference between two independent groups, effect size $0.80, \alpha$ error prop 0.05 , and a power (1- $\beta$ err prop) $90 \%$ using in dependent $t$ test to detect mean between two equal 
groups, two tails. Sample size is 68 participants (34 each group).

\subsection{Recruitment of the sample:}

One hundred and seven primigravida were screened for fulfilling the inclusion criteria; 39 out of the 107 did not fit the criteria for participation thus, excluded. Data were collected from the intervention group then from the control group, $(n=34$ per each group). During the study period, nine women dropped from the intervention group because they did not do the massage and three women in the control group were missed during the follow-up. The dropped number $(n=12)$ were replaced with the next potential subjects. The statistical analysis was done on 68 participants. The flowchart of the study sample indicated in Figure (1). 
A total number of 107 were screened for eligibility

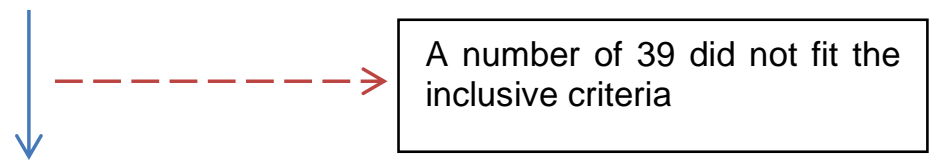

A number of 68 women were eligible for participation
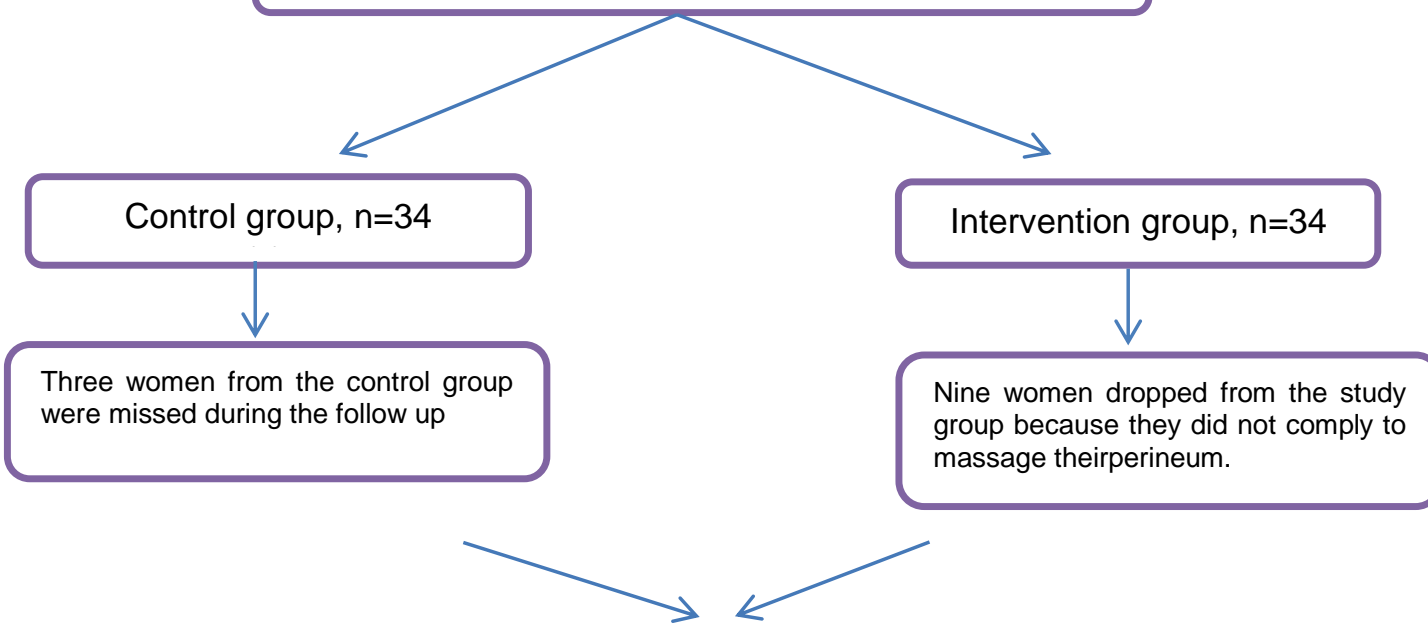

The dropped women from both groups $(\mathrm{no}=12)$ were replaced

The statistical analysis was done on 68 participants

Figure 1 Flow chart of the participants. 


\subsection{Tools of data collection:}

To achieve the aim of this study, two tools were utilized to collect data; the first tool was developed by the researchers after reviewing related literature, while second tool was adopted from Chung et al. $(2013)^{(18)}$ andOwais \& Kalsoom $(2015)^{(19)}$. Then, the required data collected through an individual interview between the researcher and each participant woman.

\section{Tool I: Structured interview Schedule}

It was developed to assess pregnant women' general characteristics as maternal age, educational level, body mass index, pre pregnancy weight, gestational age, and evaluating the strength of pelvic-floor muscle using brink scale.

Brink scale compromised three subscales for evaluating pelvic-floor muscle contraction including the squeezing pressure around the examiner's fingers, the duration and vertical displacement of the examiner's fingers. Each subscale is rated separately on a four-point categorical scale and the ratings are then added together to give a composite rating from three to twelve. The lowest score was three to six whereas the moderate score was seven to nine and the highest score was ten to twelve on ordinal scale, the higher score indicates better muscle function ${ }^{(\mathbf{2 0})}$.

Tool II: Assessment Sheet:

It entails three parts: part one; included details about the current delivery (e.g., labor onset and duration of labor. Part two; concerned with perineal state which incorporated perineal condition after labor (e.g. intactness of perineum, episiotomy, degree of perineal tears). Also, this part was concerned with the assessment of postpartal perineal pain using Numeric Pain Intensity Scale (NPIS).NPIS is a horizontal line numbered from zero to ten, where zero interpreted as "no pain", one to three as "mild pain", four to six as "moderate pain" and seven to ten as "severe pain" (18).

Part three; to assess neonatal condition after delivery by Apgar scoring, it is an observer scale adapted from Owais \& Kalsoom., (2015) $)^{(19)}$ andis used to assess neonatal' conditions, in which each neonate was observed by the researcher at the 1 st $\& 5^{\text {th }}$ minutes after delivery for skin color, heart rate, reflexes, muscle tone \&breathing rate and effort. Each one of the five items scored as zero, one, or two. The minimum score is zero and a maximum score is ten (the baby who scored eight or more points was considered good, while a baby who scored less than eight points was considered low).

\subsection{Validity of the tools}

The content of the developed questionnaire was validated and confirmed by a panel of three specialists in maternity nursing and 
obstetrics before it was presented to pregnant women. Their views on the consistency, accuracy and relevancy of the tools, thus, nomodifications were needed.

\subsection{Reliability of the tools}

Tool two was assessed by using Cronbach's Alpha coefficient test. It consisted of relatively homogeneous items as indicated by the high reliability, where its internal consistency was 0.81 .

\subsection{Pilot study:}

Before the beginning of data collection, a pilot study was carried out on $10 \%$ (7 subjects) of the total sample size according to the selection criteria to test the clarity; effectiveness and applicability of the tools. Subjects from the pilot study were omitted from the study sample.

\subsection{Ethical considerations:}

Ethical consent was gained from the Research Ethics Committee of the Faculty of Nursing at the University of Mansoura. Written agreement was obtained from each participant involved in the study after clarifying its goal and approach. Privacy was protected by providing the perineal massage training and collecting the required data through an individual face to face interview in a single private room. Confidentiality of data was maintained as the collected data were stored on a password-protected file on the main investigator's personal computer and data were permanently deleted after statistical analysis. Also, the collected data did not touch the moral and religious aspects of the enrolled clients.

\subsection{Field work:}

Three phases were followed to accomplish the study including preparatory, implementation phases and outcome evaluation.

\section{A. Preparatory phase:}

Literature reviewing were done to identify the effect of applying late pregnancy selfperineal massage on perineal state and the duration of labor (using the available periodicals, books and internet resources) to get acquainted with the various aspects of the study problem and to prepare the necessary tools for data collection. Then, the pilot study was performed to test the clarity and applicability of the tools.

\section{B. Implementation phase}

\section{The initial assessment:}

At this phase, subjects were interviewed by one of the researchers to explain the aim of the study, insure eligibility, and take their consent to participate in the study. After that, the researcher completed the data of interviewing schedule and brink scale. The subjects were interviewed two days/week (Sunday and Wednesday), at the study setting, each interview took about 20 to 30 minutes with each subject. 


\section{Intervention:}

Control group: subjects in the control group received routine antenatal care as dictated by the hospital policy (booking, complete physical examination and routine laboratory tests)

Intervention group: the subjects in the intervention group provided both routine antenatal care and instructions about late pregnancy self-perineal massage. Each pregnant woman was instructed to do perineal massage as follows ${ }^{(21,22)}$;

a) Empty the bladder and wash hands to be free from germs.

b) Find a private room to relax in then sits and widely open the legs with bended knees, using a mirror to easily visualizing vaginal opening and the perineum.

c) Apply a hypoallergenic lubricant on the thumb as KY jelly.

d) Gently insert the lubricated thumb about three to five $\mathrm{cm}$ into the vagina, pushing it towards the anus and the sides of the vagina at the same time to stretch the opening for a minute or two or until slight burningis felt (this is normal and decreases over time).Massage with the thumbs upward and outward then back again in a U-shaped movement. e) Perform the massage with a slow, deep breath and repeat two times / week.

f) In case of feeling uncomfortable or having abnormal signs (vaginal discharge or itching), stop doing the massage.

Meanwhile, during the study period, the researcher was in contact with the participants by telephone to answer their questions and follow them to ensure that they were doing the massage procedure.

\section{Outcome evaluation}

At the time of delivery, each participant was assessed through the $2^{\text {nd }}$ tool (assessment sheets) to estimate the primary labor outcomes as onset and duration of labor. Also, neonatal outcomes were assessed after completion of delivery using Apgar score. Likewise, perineal state was assessed for episiotomy, perineal tears and postpartal perineal pain level (after the first 24 hours of labor and at the $10^{\text {th }}$ postpartal day via phone). Accordingly, a comparison was done to assess the differences between the control and intervention groups related to the effect of late pregnancy self-perineal massage on the perineal state of the subjects.

\subsection{Statistical analysis}

All data were analyzed using the SPSS package version 20.0 under windows. Variables continuing continuous data showed normal distribution and described 
as arithmetic mean \pm standard deviation (SD). Frequency and percentage were used to describe variables containing categorical data. Means were compared by Independent variable Student's $t$ test. Frequencies were compared using Chisquare test. $\mathrm{P}$ value $<0.05$ indicates statistical significance.

\subsection{Limitation of the study}

The limitation for the current study was the time wasted on convincing the subject's to do per-vaginal examination before recruitment to evaluate the strength of pelvic-floor muscle and insure eligibility for the study. Another limitation was that necessary national references were lacking; thus, the researcher had difficulties in discussing the research topic

\section{Results}

Table (1) shows no statistically significant difference observed between the studied groups regarding their socio- demographic characteristics. Both groups were to some extent similar based on maternal age, educational level, the mean Body Mass Index (BMI), and brink scale score. The current study findings revealed that, more than one third $(38.2 \% \& 41.2 \%)$ of the study and the control groups, respectively, were 26-30 years old and more than the half $(58.8 \%)$ of the intervention group were university graduates compared to only $32.4 \%$ of the control group. It was clarified that the mean BMI was $21.764 \pm$ 2.075 and $21.264 \pm 1.943$ for both massage and control groups, respectively, while, the mean for brink scale score was $10.882 \pm$ $0.91311 .058 \pm 0.850$ and $11.058 \pm 0.850$ among the perineal massage and the control groups, respectively.

Table (2) sheds light on the distribution of the subjects according to their labor event. It was noticed that more than three quarters (79.4\%) of the perineal massage group had spontaneous labor compared to $58.8 \%$ of the control group. More than one half of both the perineal massage and the control groups $(57.2 \%$ \& $57.1 \%$ respectively) where inducted by oxytocin. There was a significant difference observed between both the study and the control groups, respectively, regarding the mean of the second stage duration where $(\mathrm{p}=0.000)$.

Table (3) exhibits the distribution of the parturients according to their perineal state. It was noticed that, more than three quarters $(76.5 \%)$ of massage group delivered without episiotomy compared to nearly $55.9 \%$ in the control group. Also, about $82.4 \%$ of the study group had intact perineum compared to only $64.7 \%$ of the control group, astatistical significant difference was noticed between both groups $(\mathrm{p}=0.017)$.

Figure (2) shows that the perineal massage group reported milder postpartal perineal 
pain than the control group 24 hours after delivery. Furthermore, it was observed that the majority $(85.3 \%)$ of subjects inperineal massage group experienced no pain at the $10^{\text {th }}$ postpartum day compared to $58.8 \%$ in the control group. There was a significant difference between both the study and the control groups, respectively, regarding their pain level at the 10th postpartum day where $\mathrm{MCP}=0.014$.

Figure (3) clarifies the comparison of neonatal Apgar scores at the $1^{\text {st }}$ and the $5^{\text {th }}$ minutes after birth. The study findings revealed that, the mean neonatal Apgar score at the $1^{\text {st }}$ minute of birth was7.735 \pm 0.665 and $7.235 \pm 0.430$ in perineal massage and control groups, respectively, while it was $9.147 \pm 0.359$ and8.882 \pm 0.537 at the $5^{\text {th }}$ minute. Apgar scoreswas statistically significant difference between both groups at the $1^{\text {st }}(\mathrm{P}=0.000)$ and the $5^{\text {th }}$ $(\mathrm{P}=0.020)$ minutes of birth. 
Table 1: Distribution of the parturients according to their general characteristics

\begin{tabular}{|l|c|c|c|c|c|}
\hline \multirow{2}{*}{ Variables } & \multicolumn{2}{|c|}{ Study group } & \multicolumn{2}{c|}{ Control group } & Significance \\
test
\end{tabular}
$0.05^{*}$

Table 2: Distribution of the parturients according to their labor event

\begin{tabular}{|c|c|c|c|c|c|}
\hline \multirow[b]{2}{*}{ Variables } & \multicolumn{2}{|c|}{ Study group } & \multicolumn{2}{|c|}{ Control group } & \multirow{2}{*}{$\begin{array}{c}\text { Significance } \\
\text { test }\end{array}$} \\
\hline & No (34) & $\%$ & No (34) & $\%$ & \\
\hline $\begin{array}{l}\text { Labor onset } \\
\text { - Spontaneous } \\
\text { - } \text { Induced }\end{array}$ & $\begin{array}{c}27 \\
7\end{array}$ & $\begin{array}{l}79.4 \\
20.6\end{array}$ & $\begin{array}{l}20 \\
14\end{array}$ & $\begin{array}{l}58.8 \\
41.2\end{array}$ & $\begin{array}{c}\mathrm{p}=0.0 .050 * \\
\mathrm{X}^{2}=3.376\end{array}$ \\
\hline $\begin{array}{l}\text { Type of induction } \\
\text { - Oxytocin } \\
\text { - Artificial rupture of } \\
\text { membranes }\end{array}$ & $\begin{array}{c}\text { No }=7 \\
4 \\
3\end{array}$ & $\begin{array}{l}57.2 \\
42.8\end{array}$ & $\begin{array}{c}\text { No }=\mathbf{1 4} \\
8 \\
6\end{array}$ & $\begin{array}{l}57.1 \\
42.9\end{array}$ & $\begin{array}{c}\mathrm{p}=0.249 \\
\mathrm{X}^{2}=1.187\end{array}$ \\
\hline Mean $2^{\text {nd }}$ stage duration (min) & \multicolumn{2}{|c|}{$54.411 \pm 3.105$} & \multicolumn{2}{|c|}{$57.176 \pm 2.989$} & $\begin{array}{c}\mathrm{p}=0.000^{* *} \\
\mathrm{t}=-3.740\end{array}$ \\
\hline
\end{tabular}

$\mathrm{X}^{2}=$ Chi square test, significance considered if $p$ value less than $0.05^{*}, \mathrm{t}=$ Independent $\mathrm{t}$ test, significance considered if $p$ value less than 0.05 
Table 3: Distribution of the parturients according to their perineal state

\begin{tabular}{|l|c|c|c|c|c|}
\hline \multirow{2}{*}{ Variables } & \multicolumn{2}{|c|}{ Study group } & \multicolumn{2}{c|}{ Control group } & Significance \\
test
\end{tabular}

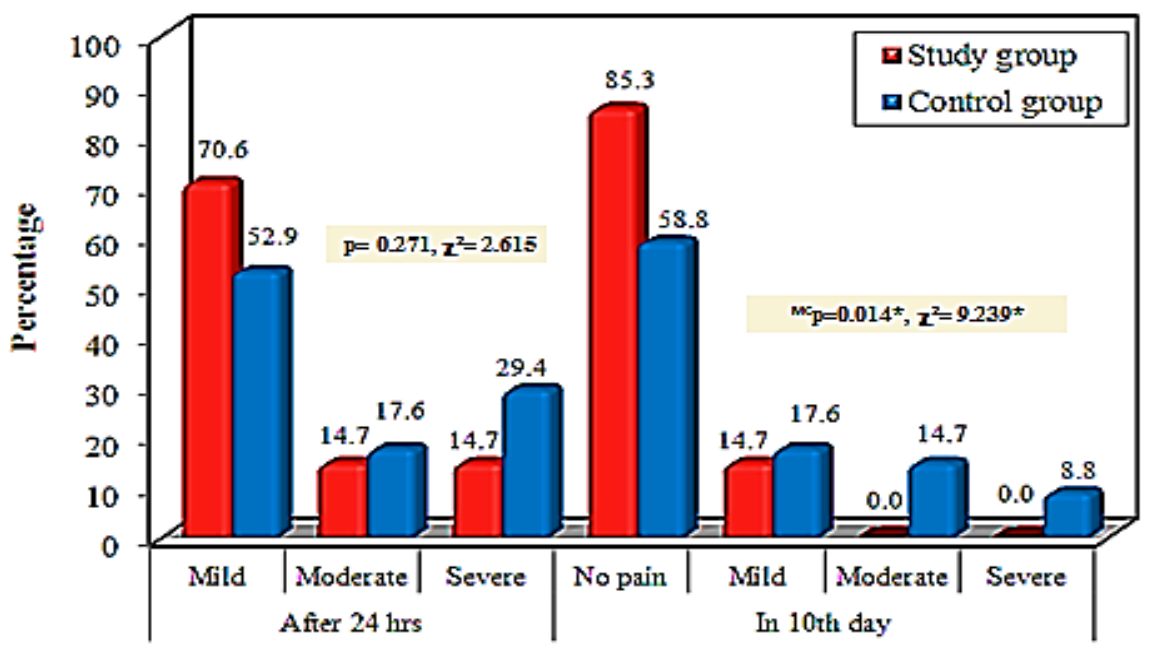

Figure (2) Comparison of postpartal perineal pain level among parturients at the first 24 hours after delivery and at the $10^{\text {th }}$ postnatal day

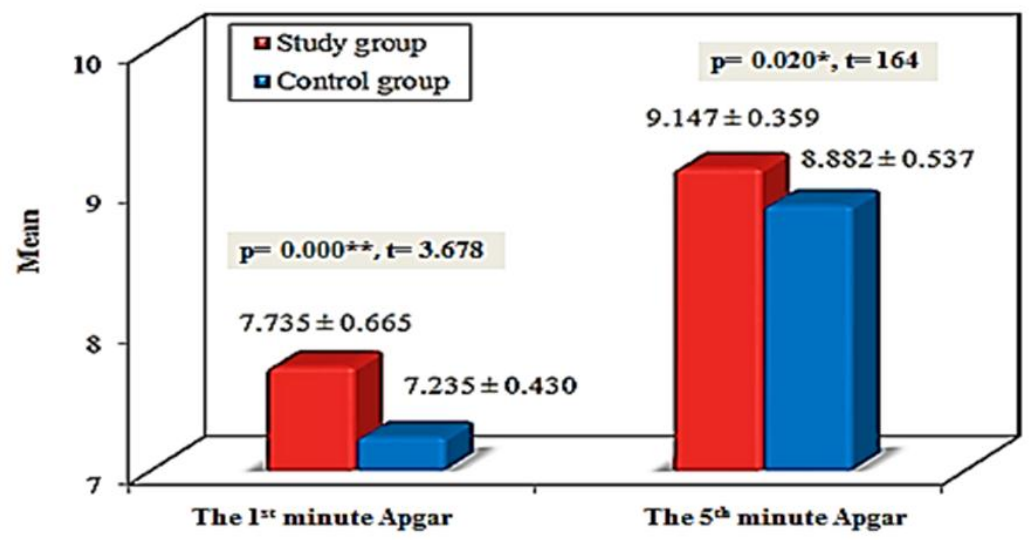

Figure (3) Comparison of neonatal Apgar score at the first and the fifth minutes after birth 


\section{Discussion}

Perineal trauma is common in childbirth, especially among the first-time mothers (23). Stress incontinence, fecal incontinence, delayed wound healing, infection; postpartum dyspareunia, rectovaginal fistulas are all linked to perineal injuries, which cause the most morbidity. All these morbidities can adversely affect postpartum recovery and maternal bonding with their neonates $\left.{ }^{(24,}{ }^{25}\right)$.In addition, episiotomy is not recommended as a routine procedure due to a lack of objective evidence-based data that support its usage andit is not effective in preventing serious perineal injuries; on the contrary, episiotomy may increase the incidence of perineal trauma and delays its healing $\mathbf{( 2 6 , 2 7 )}$. Self-perineal massage in late pregnancy is among the interventions proposed to improve postpartum perineal outcomes ${ }^{(2,28)}$.

The presentstudy aimed to assess the effect of late pregnancy self-perineal massage on the perineal state of the primiparturients, this aim was achieved. The results of the current study showed that the average duration of the $2^{\text {nd }}$ stage of labor in the perineal massage group was much shorter than the control group. Consequently, the first study hypothesis"primi-parturient women who perform late pregnancy self-perineal massage exhibit shorter duration of labor

than those who do not" isaccepted. This findingsare in line with Abdelhakim, et al (2020) $^{(2)}$ and Oglak \&OBU $(\mathbf{2 0 2 0})^{(\mathbf{2 9})}$,reported that the duration of the $2^{\text {nd }}$ stage of labor was significantly lower in the perineal massage group than control group.

Again the current findings are matched with Raja, et al (2019) ${ }^{(30)}$ reported that, the mean duration of $2^{\text {nd }}$ stage of labor in the massage group was significantly shorter than in the control group. Furthermore, Elsebeiy et al (2018)(31) in Egypt conducted randomized controlled trial, reported a highly statistically significant reduction the average duration of the $2^{\text {nd }}$ stage of labor in the perineal massage and kegel exercise group compared to the control group. These results can be attributed to the fact that perineal massage stimulates both tissue rehabilitation and muscle elasticity. Also, it has a good impact on vaginal delivery due to its effects on vaginal tissues and muscles of the perineal area, encouraging perineal relaxation, and enhancing tissue circulation. All of these cumulative effects make it easier for the parturient to "push 
her baby out". Consequently, enhance labor progress and reduce its duration ${ }^{(32)}$. In contrast, Dieb, et al (2019)(33), didn't found significant difference in the duration of the $2^{\text {nd }}$ stage of labor between perineal massage and control groups .The differences in the findings may be related to the fact that the length of the second stage of labor in multiparous women shorter than in primiparous women ${ }^{(\mathbf{3 4}, 35)}$. However,Dieb, et al (2019) ${ }^{(33)}$,had performed perineal massage on multiparous women, while, the present study was performed on primiparturients.

The current study showed that the incidence of perineal tears $\&$ episiotomywas considerably lower in the perineal massage group than in the control group. So, the second study hypothesis "primi-parturient women who perform late pregnancy self-perineal massage experience lower perineal trauma than those who do not"is accepted. This finding is somewhat consistent with Dieb, et al, $\mathbf{( 2 0 2 0}^{(\mathbf{3 3})}$, stated that the perineal massage group had a lower incidence of a perineal tears than the control group. Another study by $\boldsymbol{U g w u}$, et al (2018) ${ }^{(\mathbf{3 6})}$, concluded that approximately one half of the subjects in the massage group suffered perineal injuries compared to more than two thirds of the those in control group.
Similarly, a study by Oglak \& $\boldsymbol{O B U}$ $(\mathbf{2 0 2 0})^{(29)}$,proved that perineal trauma rates were significantly lower in the perineal massage group than in the control group. Such finding may be attributed to the beneficial effects of perineal massage when performed through the last four weeks before the due date.It promotes perineal tissueblood flow, decreases tissue restriction and improves flexibility of perineal muscle. Consequently perineum's integrityis maintained during labor and the perineum is allowed to be stretched during labor without tearing or without the need for episiotomy as well as reducing the severity of potential perineal lacerations (37).

In contrast,Stamp, et al, $2001{ }^{(38)}$, did not find any significant difference between perineal massage group and control group in terms of the frequency of episiotomy and intactness of the perineum. The differences in the findings may be related to that the positive effect of perineal massage was most obvious when it was done during pregnancy at least four weeks before delivery date for greater elasticity of tissues during labor ${ }^{(\mathbf{1 3}, 39)}$ However, Stamp, et al, $2001{ }^{(38)}$,had performed perineal massage during the second stage of labor, while, the present study was performed in the later weeks of pregnancy. 
According to the results of the current study, the rate of the $1^{\text {st }}$ and the $2^{\text {nd }}$ degree perineal tears was much higher in the massage group than in the control group, while the rate of $3^{\text {rd }}$ and $4^{\text {th }}$ degree tears was only noticed in the control group. It can be stated that the findings of this study is somewhat in harmony with other several studies: the first one by Dieb, et al $\mathbf{( 2 0 2 0}^{(\mathbf{3 3})}$, showed that the massage group had a greater rate of the $1^{\text {st }}$ degree perineal tears, while the $2^{\text {nd }}, 3^{\text {rd }}$, and $4^{\text {th }}$ degree perineal tears were higher in the control group. Likewise, a study byOglak \& $\boldsymbol{O B U}(\mathbf{2 0 2 0})^{(29)}$, stated that the rate of $1^{\text {st }}$ and $2^{\text {nd }}$ degree perineal tears was higher in the massage group than in the control group.In addition, none of the subjects in the massage group developed $3^{\text {rd }}$ and $4^{\text {th }}$ degree perineal tears.

The current study results still in the same line with the findings of Abdelhakim, et al (2020) (2) and Shahoei, et al (2017) (9)found that massaging of perineum during pregnancy decreases the incidence of the $3^{\text {rd }}$ andthe $4^{\text {th }}$ degree of perineal tears. Authors of the present study back these findings to the fact that perineal massage is supposed to improve perineal outcomes by enhancing tissue circulation, promoting perineal relaxation and flexibility, thus, making it easily for vaginal and perineal tissues to be easily extended during labor and reducing the risk of the perineum and vaginal injuries (40).

Regarding postpartal perineal pain, the current study findings showed that the subjects in the massage group reported milder pain than those in control the group within the $1^{\text {st }} 24$ hours after delivery. But, after the $10^{\text {th }}$ postpartal day, no pain was reported in the majority of the intervention group compared to less than three quarters of the control group. Accordingly, the third study hypothesis "primi-parturient women who perform late pregnancy selfperineal massage rate lower perineal pain than those who do not" is accepted. These findings are congruent with Dieb, et al $\mathbf{( 2 0 1 9}^{(\mathbf{3 3})}$, reported that the majority of the massage grouphad mild pain in the $1^{\text {st }} 24$ hours and after the $10^{\text {th }}$ day of postpartum period no pain was reported.

Likewise findings by Beckmann (2013) (13), reported that, perineal pain was observed to be reduced by perineal massage in the $1^{\text {st }} 24$ hours and after the $10^{\text {th }}$ day of vaginal delivery. Authors of the present study, attribute evidenced pain reduction in subjects of the intervention group to that massaging of the perineum can be helpful in a vaginal delivery as it reduces perineal tissue rigidity and flexibility, improves perineal blood flow, decreases the risk of tearing and surgical 
cutting as well as promoting perineal repair. Consequently, perineal massage helps desensitize women to feel perineal burning and/or pain during labor and postpartum period ${ }^{(37)}$.

The findings of the study revealed that the neonates in the perineal massage group had a significantly higher Apgar scores in both the $1^{\text {st }}$ and the $5^{\text {th }}$ minutes after delivery than those in the control group. This is in coherence with the findings of previous studies byAbdelhakim, et al (2020)(2), Dieb, et al $(2020)^{(33)}$ \&Elsebeiy, et $\operatorname{al}(\mathbf{2 0 1 8})^{(31)}$ concluded that massage groups had higher statistical significance difference in terms of the mean $1^{\text {st }}$ and $5^{\text {th }}$ minutes Apgar scores than those in control groups. The amelioration in Apgar scores following antenatal perineal massage can be attributed tothat, the better perineal elasticity, the shorter second stage of labor and less difficult delivery thusreduced the risk offetal hypoxia during labor.

\section{Nursing implications for practice}

Generally, self-perineal massage in the latter weeks of pregnancyappears to be safe, simple, low-cost, and effective technique that can be utilized by maternity nurses as one of the nursing strategies that promotes perineal elasticity, reducesthe perineal damage during delivery and shorten the duration of labor as well as decreases postpartal perineal pain.

\section{Conclusion}

In conclusion, primi-parturient women who perform self-perineal massage in the latter weeks of pregnancy exhibits shorter duration of labor and experience lower perineal trauma as well as reports lower postpartal perineal pain, accordingly, the current study hypotheses was accepted.

\section{Recommendations}

In light of the study finding, the following recommendations are suggested:

- Late pregnancy self-perineal massage technique should be considered as a part of the routine perinatal care to reduce the incidence of perineal trauma.

- Further studies are needed to assess parturients' satisfaction regarding the use of the late pregnancy self-perineal massage. Also,the current study should be conducted on a wide range of sample in multicenter settings to be generalized.

\section{Acknowledgments}

The authors would like to thank and appreciate the respected personnel staff of El- Mahalla El -Kobra hospital and the pregnant women who accepted to participate in the study for their invaluable assistance during the study. 


\section{Conflicts of interest disclosure}

The authors have no conflict of interest to declare.

\section{References}

1. Sandall, J., Soltani, H., Gates, S., Shennan, A., \& Devane, D. (2015).

Midwife-led continuity models versus other models of care for childbearing women. The cochrane database of systematic reviews, 9, cd004667. https://doi.org/10.1002/14651858.CD0 04667.pub4.

2. Abdelhakim, A. M., Eldesouky, E., Elmagd, I. A., Mohammed, A., Farag, E. A., Mohammed, A. E., Hamam, K. M., Hussein, A. S., Ali, A. S., Keshta, N.

H. A., Hamza, M., Samy, A., \& Abdel-Latif, A. A. (2020). Antenatal perineal massage benefits in reducing perineal trauma and postpartum morbidities: a systematic review and meta-analysis of randomized controlled trials. International urogynecology journal, 31(9), 1735-1745. Https://doi.org/10.1007/s00192-02004302-8

3. Kalichman, L. (2008). Perineal massage to prevent perineal trauma in childbirth. The israel medical association journal, 10(7), 531-533.

4. Belihu, F. B., Small, R., \& Davey, M. A. (2017). Episiotomy and severe perineal trauma among eastern african immigrant women giving birth in public maternity care: a population based study in victoria, australia. Women and birth, 30(4), 282-290. Https://doi.org/10.1016/j.wombi.2016. 11.008 .

5. Mikolajczyk, R. T., Zhang, J., Troendle, J., \& Chan, L. (2008). Risk factors for birth canal lacerations in primiparous women. American journal of perinatology, 25(5), 259-264. Https://doi.org/10.1055/s-20081075040.

6. Okeke, T. C., Ugwu, E. O., Okezie, O. A., Enwereji, J. O., Ezenyeaku, C. C., \& Ikeako, L. C. (2012). Trends and determinants of episiotomy at the university of nigeria teaching hospital (unth), enugu, nigeria. Nigerian journal of medicine, 21(3), 304-307.

7. Mohamed, A. H. G. (2016). Risk factors for birth related perineal truama among low risk parturient women and nursing implications. Iosr journal of nursing and health science, 5(1), 40-48. Https://doi.org/10.9790/195905114048 .

8. Hedayati, H., Parsons, J., \& Crowther, C. A. (2005). Topically applied anaesthetics for treating perineal pain after childbirth. The cochrane database of systematic 
reviews, $\quad 2, \quad \operatorname{cd} 004223$.

Https://doi.org/10.1002/14651858.cd00 4223.pub2.

9. Shahoei, R., Zaheri, F., Nasab, L. H., \& Ranaei, F. (2017). The effect of perineal massage during the second stage of birth on nulliparous women perineal: a randomization clinical trial. Electronic physician, 9(10), 55885595. Https://doi.org/10.19082/5588.

10. Moore, E., \& Moorhead, C. (2013). Promoting normality in the management of the perineum during the second stage of labour. British journal of midwifery, 21(9), 616-620. Https://doi.org/10.12968/bjom.2013.21 9.616 .

11. Laine, K., Räisänen, S., \&\&Kalis, V. (2016). Intrapartum interventions and risk of perineal trauma. In k. M. K. Ismail (ed.), perineal trauma at childbirth (p.p. 83-96). Springer international publishing

12. Labrecque, M., Eason, E., \& Marcoux, S. (2000). Randomized trial of perineal massage during pregnancy: perineal symptoms three months after delivery. American journal of obstetrics and gynecology, 182(1 pt 1), 76-80. Https://doi.org/10.1016/s00029378(00)70493-5.

13. Beckmann, M. M., \& Stock, O. M. (2013). Antenatal perineal massage for reducing perineal trauma. The cochrane database of systematic reviews, 4, cd005123.

Https://doi.org/10.1002/14651858.cd00 5123.pub3.

14. Seehusen, D. A., \& Raleigh, M. (2014). Antenatal perineal massage to prevent birth trauma. American family physician, 89(5), 335-336.

\section{Mosad S., Youssef N., Shams Elden} M, \& Fikry N. (2017). Practices that applied on protection of perineal trauma among parturient women." Iosr journal of nursing and health science (iosr-jnhs) vol. 6, no.5, pp. 88-95. Doi: 10.9790/1959-0605098895)

16. Anne, K. T. (2020). The effectiveness of prenatal perineal massage at reducing the risk of perineal trauma during vaginal delivery: a metaanalysis [doctoral thesis]. Department of physical therapy, health and human services college, california state university.

17. Mei-dan, E., Walfisch, A., Raz, I., Levy, A., \& Hallak, M. (2008). Perineal massage during pregnancy: a prospective controlled trial. The israel medical association journal, 10(7), 499-502.

18. Chung D, Lee YJ, Jo MH, Park HJ, Lim GW, Cho H, Nam EJ, Kim SW, Kim JH, Kim YT, Kim S. (2013). The 
on-q pain management system in elective gynecology oncologic surgery: management of postoperative surgical site pain compared to intravenous patient-controlled analgesia. Obstet gynecol sci. 56(2):93-101.

19. Owais MA., \& Kalsoom U., (2015). Effect of maternal anemia on apgar score of newborn. Journal of rawalpindi medical college (jrmc);19(3):239-242

20. Naqaish T., Rizvi F., \& Iqbal JK., (2013).Impact of kegel exercise on brink scale and activities of daily life (adls) in patients of cystocele. Journal of rawalpindi medical college (jrmc);17(2):243-246

\section{Oxford University Hospitals NHS} Trust (2017). Antenatal perineal massage. Available at: https://www.ouh.nhs.uk/patientguide/le aflets/files/10938pmassage.pdf [access ed 1st august 2o2o]

22. American College of NurseMidwives (2016). Perineal massage in pregnancy. J midwifery women's health. 61(1):143-144. Available at: https://onlinelibrary.wiley.com/doi/f ull/10.1111/jmwh.12427 [accessed 1st august 2o2o]

23. Vale de Castro Monteiro, M., Pereira, G. M., Aguiar, R. A., Azevedo, R. L., Correia-Junior, M.
D., \& Reis, Z. S. (2016). Risk factors for severe obstetric perineal lacerations. International urogynecology journal, 27(1), 61-67. Https://doi.org/10.1007/s00192-015-27955.

24. Edozien, L. C., Gurol-Urganci, I., Cromwell, D. A., Adams, E. J., Richmond, D. H., Mahmood, T. A., \& van der Meulen, J. H. (2014). Impact of third- and fourth-degree perineal tears at first birth on subsequent pregnancy outcomes: a cohort study. British journal of obstetrics and gynaecology, 121(13), 1695-1703.

Https://doi.org/10.1111/14710528.12886 .

25. Das, B., \& Snyder, M. (2016). Rectovaginal fistulae. Clinics in colon and rectal surgery, 29(1), 50-56. Https://doi.org/10.1055/s-00351570393.

26. Berghella, V. (2020). New series of reviews on evidence-based $1 \& d$ management and cesarean delivery! American journal of obstetrics \& gynecology mfm, 2(1), 100079. Https://doi.org/10.1016/j.ajogmf.2019.100 079

27. Jiang, H., Qian, X., Carroli, G., \& Garner, P. (2017). Selective versus routine use of episiotomy for vaginal birth. The cochrane database of 
systematic reviews, 2(2), cd000081. Https://doi.org/10.1002/14651858.cd00 0081.pub3.

28. Woodley, S. J., Boyle, R., Cody, J. D., Mørkved, S., \& Hay-Smith, E. J. C. (2017). Pelvic floor muscle training for prevention and treatment of urinary and faecal incontinence in antenatal and postnatal women. The cochrane database of systematic reviews, 12(12), cd007471.

Https://doi.org/10.1002/14651858.cd00 7471.pub3.

29. Oglak, S. C., \& Obut, M. (2020). Effectiveness of perineal massage in the second stage of labor in preventing perineal trauma. Gynecology obstetrics $\&$ reproductive medicine, 26(2), 88-93. Https://doi.org/10.21613/gorm.2020.10 68.

30. Raja, A., Pallavee, P., \& Samal, R. (2019). Effect of perineal massage in the second stage of labour, on the incidence of episiotomy and perineal tears. International journal of reproduction, contraception, obstetrics and gynecology, 8(4), 1387-1392. Https://doi.org/10.18203/23201770.ijrcog20191186.

31. Elsebeiy, F. I. (2018). Comparison of the effects of prenatal perineal massage versus kegel exercise on labor outcome. Iosr journal of nursing and health science, $7(3), \quad 43-53$. Https://doi.org/10.9790/19590703034353.

32. Demirel, G., \& Golbasi, Z. (2015). Effect of perineal massage on the rate of episiotomy and perineal tearing. International journal of gynaecology and obstetrics, 131(2), 183-186. Https://doi.org/10.1016/j.ijgo.2015.04. 048

33. Dieb, A. S., Shoab, A. Y., Nabil, H., Gabr, A., Abdallah, A. A., Shaban, M. M., \& Attia, A. H. (2020). Perineal massage and training reduce perineal trauma in pregnant women older than 35 years: a randomized controlled trial. International urogynecology journal, 31(3), 613-619.

Https://doi.org/10.1007/s00192-01903937-6.

34. Rosenbloom, J. I., Rottenstreich, A., Yagel, S., Sompolinksy, Y., \& Levin, G. (2020). The length of the second stage of labor in nulliparous, multiparous, grand-multiparous, and grand-grand multiparous women in a large modern cohort. European journal of obstetrics, gynecology, and reproductive biology, 253, 273277.https://doi.org/10.1016/j.ejogrb. 20 $\underline{20.08 .029}$

35. Sharma, R. (2019). Stages of Labor and Nursing Care. Available 
at,https://www.researchgate.net/publica tion/335518026_Stages_of_Labor_and _Nursing_Care/citation/download. Last acceded, 30-8-2021.

36. Ugwu, E. O., Iferikigwe, E. S., Obi, S. N., Eleje, G. U., \& Ozumba, B. C. (2018). Effectiveness of antenatal perineal massage in reducing perineal trauma and post-partum morbidities: a randomized controlled trial. The journal of obstetrics and gynaecology research, 44(7), 1252-1258. Https://doi.org/10.1111/jog.13640.

37. Dame, J., Neher, J., Safranek, S., \& Huber, T. E. (2008). Clinical inquiries. Does antepartum perineal massage reduce intrapartum lacerations? The journal of family practice, 57(7), 480-481.

38. Stamp, G., Kruzins, G., \& Crowther, C. (2001). Perineal massage in labour and prevention of perineal trauma: randomised controlled trial. BMJ (Clinical research ed.), 322(7297), $1277-$

1280.https://doi.org/10.1136/bmj.322.7 297.1277

39. Dönmez, S., \& Kavlak, O. (2015). Effects of prenatal perineal massage and kegel exercises on the integrity of postnatal perine. Health, 7(4), 495-505. Https://doi.org/10.4236/health.2015.74 059
40. Albers, L. L., \& Borders, N. (2007). Minimizing genital tract trauma and related pain following spontaneous vaginal birth. Journal of midwifery \& women's health, 52(3), 246-253. Https://doi.org/10.1016/j.jmwh.2006.1 2.008. 